The incidence of treatment-emergent adverse events (AEs) was comparable between APR and PBO during the PBO-controlled period $(78.8 \%$ vs $71.8 \%$, respectively). Serious AEs were observed in 3 APR pts (migraine, oral ulcer flare, genital ulcer, arthralgia, soft tissue injury) and 4 PBO pts (diarrhoea, genital and fungal infections, oral ulcer flare, acne, acute febrile neutrophilic dermatosis, erythema multiforme).

\begin{tabular}{|l|c|c|c|}
\hline Endpoints & $P$ Value & $\begin{array}{c}\text { Adjusted } \\
\text { Treatment } \\
\text { Difference } \\
\text { (or HR) }\end{array}$ & $\begin{array}{c}\text { APR vs. PBO } \\
\text { (LS Mean, } \\
\text { Median Time } \\
\text { or \%) }\end{array}$ \\
\hline $\begin{array}{l}\text { AUC for the number of OU from baseline } \\
\text { through Week 12 }\end{array}$ & $<0.0001$ & -92.6 & 129.5 vs. 222.1 \\
\hline $\begin{array}{l}\text { Change from baseline in the pain of OU as } \\
\text { measured by VAS at Week 12 }\end{array}$ & $<0.0001$ & -24.8 & -40.7 vs. -15.9 \\
\hline $\begin{array}{l}\text { Proportion of subjects achieving OU } \\
\text { resolution by Week 6 who remain OU free } \\
\text { for 26 additional weeks (maintenance of } \\
\text { OU resolution) }\end{array}$ & $<0.0001$ & $25.1 \%$ & $29.8 \%$ vs. $4.9 \%$ \\
\hline $\begin{array}{l}\text { Time to OU resolution, during the PBO- } \\
\text { Controlled Treatment Phase }\end{array}$ & $<0.0001$ & HR $=2.400$ & $\begin{array}{c}\text { Median time in } \\
\text { weeks: } 2.1 \text { vs. } 8.1\end{array}$ \\
\hline $\begin{array}{l}\text { Proportion of subjects achieving resolution } \\
\text { of OU at Week 12 }\end{array}$ & $<0.0001$ & $30.6 \%$ & $52.9 \%$ vs. $22.3 \%$ \\
\hline $\begin{array}{l}\text { Proportion of subjects achieving resolution } \\
\text { of genital ulcers at Week 12 for subjects } \\
\text { who had genital ulcers at baseline }\end{array}$ & 0.1100 & $28.4 \%$ & $70.6 \%$ vs. $41.2 \%$ \\
\hline
\end{tabular}

Conclusions: APR effectively reduced the number and pain of OU, improved time to oral ulcer resolution, and maintained the resolution of $\mathrm{OU}$, the most common manifestation of BS. Favourable treatment effects were also observed for genital ulcer resolution. The safety profile was consistent with the known safety profile of APR.

Disclosure of Interest: G. Hatemi Grant/research support from: Celgene Corporation, Speakers bureau: UCB, Abbvie, Mustafa Nevzat, A. Mahr Speakers bureau: Roche Chugai, M. Takeno Consultant for: Celgene Corporation, Speakers bureau: Esai Co, Tanabe-Mitsubishi Co, D.-Y. Kim: None declared, M. Melikoglu: None declared, S. Cheng Employee of: Celgene Corporation, S. McCue Employee of: Celgene Corporation, M. Paris Employee of: Celgene Corporation, Y. Wang Employee of: Celgene Corporation, Y. Yazici Consultant for: Celgene Corporation, Sanofi, Genentech, BMS

DOI: 10.1136/annrheumdis-2018-eular.5627

\section{OP0083 TEMPORAL TRENDS AND MORTALITY OF HOSPITALISEDPATIENTS WITH ADULT ONSET STILLS DISEASE: A NATIONWIDE ESTIMATE}

B Mehta $^{1,2}$, W. Briggs ${ }^{3}$, P. Efthimiou ${ }^{4} .{ }^{1}$ Hospital for Special Surgery; ${ }^{2}$ Weill Cornell Medicine; ${ }^{3}$ New York Presbyterian Hospital; ${ }^{4}$ NYU Langone Medical Center, New York, USA

Background: There is a dearth of epidemiological studies on Adult Onset Still's Disease (AOSD). Majority of studies are from single centres or are regional. The largest AOSD epidemiological study till date describes 512 patients. ${ }^{1}$

Objectives: To describe the demographics, complications, mortality and trends of hospitalised patients with AOSD in United States. Also, to understand the factors associated with mortality in these patients

Methods: All adult (>18 years) hospitalised patients between 2009 and 2013 from a nationwide inpatient sample (NIS) database were captured. AOSD patients were identified using the ICD-9 code 714.2. Patients also coded for Rheumatoid Arthritis, Lupus, Myositis, Polymyalgia Rheumatica, Ankylosing Spondylosis and Psoriatic Arthritis were excluded. This was done in order to capture patients with strictly AOSD. NIS is the largest all-payer inpatient care database in the United States with approximately 8 million hospitalizations each year. Discharge weights were used to enable nationwide estimates. Descriptive statistics were represented as means/medians for continuous and as frequencies and percentages for categorical variables. A survey weighted logistic regression model was used to describe the associations with in-hospital death.

Results: Between 2009 and 2013, 5,820 AOSD patients were hospitalised (table 1). AOSD patients had a mean age of 53.6 (SE - 0.61) years, $3817(65.6 \%)$ were females. The racial/ethnic distribution showed that $56 \%$ white, $15 \%$ African American, $11.7 \%$ Hispanic and $3 \%$ Asian patients were affected. Over the years, the number of white patients that are hospitalised seems to have increased. $37.6 \%$ were hospitalised in urban teaching hospitals. $100(1.7 \%)$ of patients developed Macrophage Activating Syndrome (MAS). 66 (1.1\%) patients had disseminated intravascular coagulation (DIC) and $25(0.4 \%)$ had thrombotic thrombocytopenic purpura (TTP). Mean length of stay was 6.9 days. There were 154 inpatient deaths in 5 years (mortality $2.6 \%$ ). The patients who died in the hospital had a higher mean age of 62.4 (SE- 3.1) years, had a higher proportion of Asians
(13.9\%) and had increased number of comorbid conditions. Asians had 6.4 times the risk of in-hospital death compared to Whites. The risk for in-hospital death is 30 times higher if a AOSD patient had concurrent DIC.

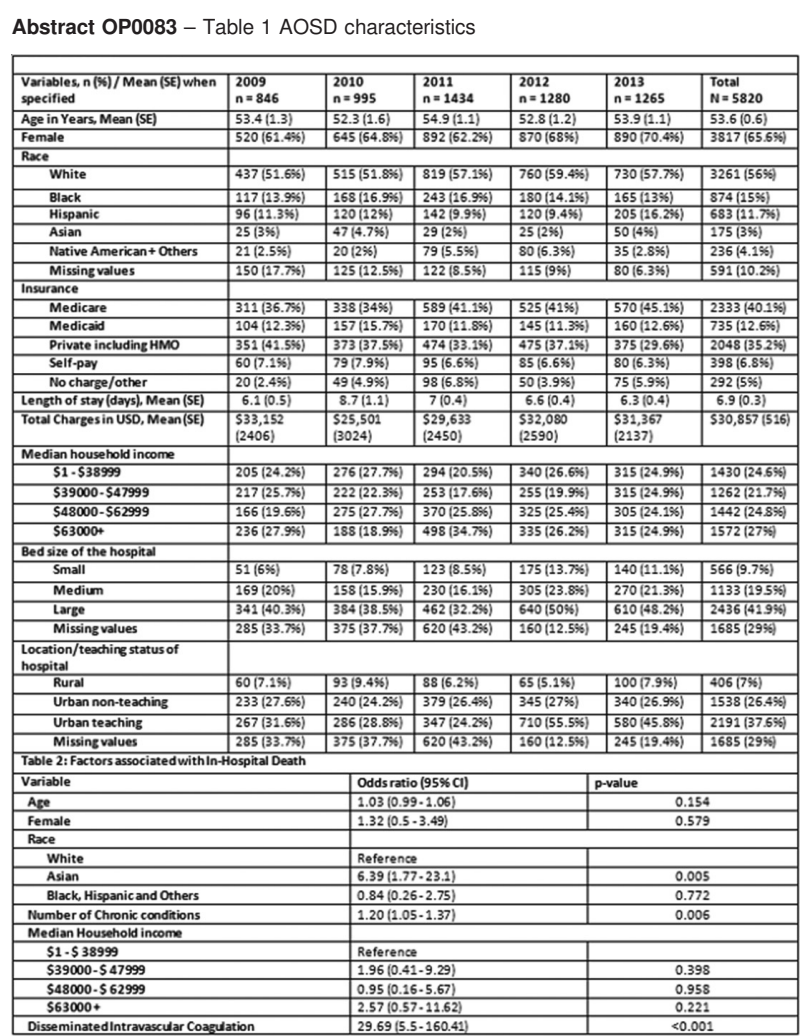

Conclusions: In hospitalised American AOSD patients, the average age was higher than previously described in cross sectional studies. This may indicate an ageing population with a higher number of comorbidities that justify hospitalisation. More patients were in large or urban teaching hospitals compared to small or rural hospitals. In-hospital death was associated with increased comorbid conditions and was significantly higher among Asians and patients with DIC. To our knowledge, this is the largest epidemiological study of AOSD.

\section{REFERENCE:}

[1] Sakata N, et al. Rheumatol Int 2016;36(10):1399-405. doi:10.1007/ s00296-016-3546-8

Disclosure of Interest: None declared

DOI: 10.1136/annrheumdis-2018-eular.2241

\section{OP0084 SERUM FIBROBLAST GROWTH FACTOR 2 IS A USEFUL BIOMARKER TO DISTINGUISH ADULT ONSET STILL DISEASE FROM SEPSIS}

T. Koga ${ }^{1}$, R. Sumiyoshi ${ }^{1}$, S. Sato ${ }^{2}$, K. Migita $^{3}$, T. Shimizu ${ }^{4}$, M. Umeda ${ }^{1}$

F. Nonaka ${ }^{5}$, S. Fukui ${ }^{1}$, S.-Y. Kawashiri ${ }^{1}$, N. Iwamoto ${ }^{1}$, K. Ichinose ${ }^{1}$, M. Tamai ${ }^{1}$, H. Nakamura ${ }^{1}$, T. Origuchi ${ }^{1}$, A. Yachie ${ }^{6}$, T. Maeda ${ }^{7}$, A. Kawakami ${ }^{1}{ }^{1}$ Division of Rheumatology, Department of Medicine; ${ }^{2}$ Clinical Research Center, Nagasaki University, Nagasaki; ${ }^{3}$ Department of Rheumatology, Fukushima Medical University School of Medicine, Fukushima; ${ }^{4}$ Department of Rheumatology, Nagasaki University, Nagasaki; ${ }^{5}$ Department of Internal Medicine, Sasebo City General Hospital, Sasebo; ${ }^{6}$ Department of Pediatrics, School of Medicine, Institute of Medical, Pharmaceutical and Health Sciences, Kanazawa University, Kanazawa; ${ }^{7}$ Department of Community Medicine, Nagasaki University Graduate School of Biomedical Sciences, Nagasaki, Japan

Background: The precise cytokine networks in the serum of individuals with adult onset still disease (AOSD) that are associated with its pathogenesis have been unknown. Serum levels of interleukin (IL) $-1 \beta$, IL -6 and IL-18 have been reported as useful serum biomarkers for diagnosis and disease evaluation among AOSD patients, ${ }^{12}$ but these cytokines are also elevated in other inflammatory diseases including severe infection. 